Le contrôle vétérinaire de la production du lait inclut cette proposition dans son programme.

Nous nous croyons donc fondé à dire que, effectuant ce contrôle en faveur de l'intérêt général, les vétérinaires peuvent et doivent assumer des fonctions essentielles au profit de l'hygiène publique en même temps que très importantes pour l'économie laitière et la production agricole.

\title{
DÉTERMINATION DE LA TENEUR DU LAIT EN «COLI-AEROGENES " PAR DES MÉTHOdES DE CULTURE EN PLAQUES
}

par

\section{S. B. THOMAS et J. M. HARCOMBE}

La détermination de la teneur du lait en Coli-aerogenes par culture sélective sur milieux solides n'a reçu que peu d'attention en Grande-Bretagne au cours de ces dernières années, quoiqu'un certain nombre de milieux à base d'agar, considérés comme convenant à ce but, aient été décrits.

Aux Etats-Unis, l'agar-bile-rouge violet et l'agar deoxycholate sont officiellement recommandés pour estimer la teneur en Coli. aerogenes du lait (1948). Le premier de ces milieux est aussi utilisé en Norvège (Hillesund, 1943) et l'agar-phosphate d'ammonium (désigné sous le nom de A.K.A. ammonium-koli-agar) pour le contrôle de la production dans les laiteries suédoises (Järvick, 1949). Au Danemark, où le test des Coli-aerogenes joue un rôle important dans l'appréciation de la qualité des fournitures de lait de ferme et du lait de consommation, l'utilisation de l'agar-bleu de méthylène-éosine, avec ou sans addition de pénicilline, a été étudiée d'une façon approfondie (MALLING OLSEN, 1952).

\section{Premières recherches.}

L'agar-lactose tournesolé a été utilisé pour estimer le nombre des bactéries Coli-aerogenes dans l'eau par SEDGEW'ICK et MATHEW's dès 1892.(MATHEW's, 1893) et ce milieu, en même temps que l'agar de MacConkey et l'agar Endo, furent utilisés pour appréciation directe sur plaques dans les premières années de la bactériologie de l'eau. Des essais furent aussi effectués pour créer des méthodes similaires pour l'examen du lait; mais on trouva que le sel biliaire,

(1) Revue de la littérature scientifique. Dairy Sc. Abs., 1954, 16, 8, 608 (traduction C. Wolf). 
inhibiteur habituel des milieux sélectifs primitifs, n'empêchait pas un certain nombre d'organismes autres que les coliformes de se développer sur le milieu. Ainsi MacConkey (1906) nota que des organismes analogues aux levures et des coci étaient capables de former des colonies sur l'agar-sel biliaire ensemencé avec du lait. Chalmers (1928) obtint des colonies de Proteus, Alcaligenes, Streptococcus faecalis et d'autres cocci sur agar lactose taurocholate utilisé pour juger sur plaques le «lait certifié ».

Un agar synthétique, spécialement conçu pour la numération et l'isolement des bactéries Coli-aerogenes par culture directe du lait sur plaques fut décrit par AyERS et RUPP (1918). Il fournissait de l'azote sous forme de phosphate d'ammonium et de sodium, du carbone sous forme de lactose, et la formation d'acide était indiquée par un mélange sulfite-fuchsine analogue à celui employé dans l'agar Endo. On l'employa comme milieu à étaler en plaque avec incubation à $37^{\circ}$ pendant 24 heures.

Une modification du milieu d'AYers et RUPP, connu comme agar-citrate-ferrocyanure fut présentée par NoBLE (1928) et TONNEY et NoBLE (1930) pour la détermination de la teneur en Coli-aerogenes de l'eau et de l'eau d'égoût. C'était un milieu à répandre en plaques exigeant une période d'incubation de 42 heures, et il fut indiqué que des colonies de Bacterium Coli pouvaient être différenciées par leur seul aspect des colonies d'autres coliformes. RUCHнотT et Coll. (1933) employèrent ce milieu pour l'examen de l'eau d'égoût, des eaux usées, des eaux de rivières polluées, de l'eau du lac Michigan et trouvèrent que les numérations directes de bactéries Coli-aerogenés étaient plus faibles que celles données par les méthodes de dilution normalisées avec bouillon lactosé et bouillon bile vert-brillant. Des colonies prélevées sur les plaques, 34 à $60 \%$ seulement de celles identifiées comme Bact. Coli furent trouvées être de cette espèce, et 51 à $82 \%$ de celles considérées comme Bact. aerogenes étaient de ce type. Les colonies de types intermédiaires ressemblaient en général à celles de Bact. Coli; - mais quelques-unes étaient analogues à des colonies de Bact. aerogenes.

SKINNER et MURRAY (1924) imaginèrent un agar à triple colorant pour l'inhibition des germes à culture envahissante et la différenciation de Bact. Coli et de Bact. aerogenes pendant l'examen des fèces, du sol et de l'eau, et Burke-GaffNey (1932) créa dans le même but un milieu d'agar peptone phosphate glucose contenant du bleu de bromothymol.

SKINNER et MURRAY utilisaient l'ensemencement superficiel de l'agar solidifié tandis que Ayekis et Rupp, Tonney et Noble et BURKE-GAFFNEY utilisaient la méthode d'étalement en plaque. Cunningham et Glathe (1933) étudièrent ces quatre milieux 
d'agar afin de déterminer si l'un d'entre eux pouvait être utilisé pour des numérations en série des bactéries Coli-aerogenes du lait. Dans tous les cas, on utilisera la méthode d'étalement en plaques, des plaques en double des différents milieux étant ensemencées avee 1 millilitre de chaque dilution et mises à l'étuve à $37^{\circ}$ pendant deux jours. Les résultats furent désappointants; le pourcentage de colonies trouvées Coli-aerogenes allait de 0 à 50 , sauf dans le cas du milieu à triple colorant pour lequel il atteignait 80 .

\section{Agar-acriflavine}

Krimmer et Coll. (1929) recommandèrent un agar lactosé au bleu de bromothymol contenant 1 pour 20.000 d'acriflavine (synonyme de trypaflavine, terme employé par eux) pour la détermination de la teneur du lait en Coli-aerogenes. Ils affirmaient que ce milieu inhibait les bactéries Gram-positives sans empêcher d'une façon appréciable le développement des bactéries Coliaerogenes, mais n'apportèrent aucune précision expérimentale détaillée à l'appui de leurs affirmations. Le milieu, après solidification, recevait des ensemencements superficiels de quantités mesurées de lait.

Cunningham et GLathe comparèrent une forme légèrement modifiée de ce milieu avẹc le milieu à triple colorant de Murray. Les résultats montrèrent qu'il était nettement supérieur à l'agar à triple colorant pour la détermination du nombre des Coli-aerogenes dans le lait. L'effet de diverses concentrations d'acriflavine fut examiné ensuite; des concentrations de 1 pour 100.000 , 1 pour $50.000,1$ pour 20.000 étant utilisées. Une caractéristique remarquable des résultats fut la proportion élevée des colonies trouvées sur les trois variantes du milieu étudiées, qui étaient des organismes Coli-aerogenes typiques. Dans presque tous les cas, cent pour cent des colonies furent trouvées être des organismes Coli-aerogenes typiques. L'incubation des plaques ensemencées par étalement durait deux jours à $37^{\circ}$. Tous les organismes non coliformes produisaient des colonies superficielles vertes à bleues et des colonies profondes brunâtres, alors que les colonies coliformes étaient de coloration jaune. Le nombre des organismes coliformes qui se développaient sur l'agar-acriflavine était aussi plus élevé que le nombre de celles qui se développaient sur l'agar à triple colorant. Des expériences sur de la bouse de vache montrèrent que pour la numération de coliformes fécaux (Bact. coli type 1) le milieu d'acriflavine à 1 pour 100.000 donnait des résultats plus sûrs que des concentrations plus élevées. Cette modification du milieu fut ensuite employée pendant l'hiver pour l'examen de plus de 100 échantillons de lait cru. 
Dans cette partie des recherches, des difficultés non éprouvées précédemment furent rencontrées. Quelques échantillons contenaient des organismes qui, quoique formant des colonies rougeâtres à jaunâtres sur le milieu acriflavine ne produisaient que peu ou pas de gaz quand on les transférait dans des tubes d'eau peptonée lactosée. De tels organismes étaient de deux types :

1. Organismes anaérogènes qui étaient des Coli typiques, des types intermédiaires ou des aerogenes, ce dernier prédominant, mais ne formant de l'acide qu'avec le lactose à $37^{\circ}$.

2. Ceux qui ne produisaient pas de quantité appréciable d'acide avec le lactose à $37^{\circ}$.

Ils en conclurent que le milieu acriflavine était le meilleur des cinq examinés, mais qu'il ne pouvait pas être recommandé pour être utilisé dans des déterminations en série de la teneur du lait en Coli-aerogenes. RüнмEкоRF (1931) affirma avoir obtenu de bons résultats avec l'agar acriflavine avec une concentration d'acriflavine de 1 pour 10.000 pour empêcher la croissance des microcoques du lait. Les colonies de Coli-aerogenes, est-il indiqué, pouvaient être clairement distinguées de celles des autres fermentateurs du lactose.

Demeter et Coll. (1933) comparèrent l'agar Endo et l'agaracriflavine avec le bouillon cristal-violet et le bouillon bile gentianeviolet et trouvèrent que l'utilisation d'agar-acriflavine constituait la méthode la plus satisfaisante de détermination du (titre Coli» du lait.

\section{Agar MacConkey}

WILson et Coll. (1935) établirent une comparaison entre la méthode de dilution dans le bouillon MacConkey et la méthode de numération sur plaques d'agar de MacConkey à $37^{\circ}$ pour déterminer le nombre des organismes Coli-aerogenes dans 120 échantillons de lait cru. Dans 9 échantillons, ni acide, ni gaz, ne furent formés dans le bouillon MacConkey ; mais dans tous des colonies se développèrent sur les plaques d'agar MacConkey. Sur les 111 échantillons restants, la numération des colonies fut plus élevée dans 82 et la numération sur bouillon, estimée d'après les tables de probabilité, fut plus élevée dans 29 échantillons. Si on prend les 120 laits, la numération arithmétique des Coli-aerogenes fut de 183.000 par millilitre par la méthode du tube de dilution et de 219.000 par la méthode sur plaque d'agar. Comme ils avaient précédemment montré que les organismes Coli-aerogenes se développent aussi bien dans le milieu liquide et solide MacConkey, ils conclurent que la numération plus élevée sur l'agar MacConkey sur lequel 
on avait étalé du lait pouvait seulement signifier que toutes les colonies rouges n'étaient pas susceptibles de former de l'ácide et du gaz dans le bouillon MacConkey.

Cette conclusion fut confirmée par l'examen d'un grand nombre de eolonies de l'agar MacConkey. On trouva fréquemment que ces colonies contenaient des organismes formant de l'acide; mais pas de gaz dans le lactose. Leur différenciation à l'œil nu des colonies de Coli-aerogenes n'était pas toujours possible et leur nature réelle ne pouvait être déterminée que par sous-culture dans des milieux sucrés. La technique impliquait la mise en plaques de quantités de un millilitre du lait entier et de dilutions en série, et les colonies rouges furent comptées après 2 jours à $37^{\circ}$. Il est possible que la, surestimation fut produite par une incubation trop prolongée et que si le nombre des colonies rouges avait été déterminé en 24 heures une estimation plus précise des bactéries Coli-aerogenes aurait été obtenue.

\section{Agar-bile-lactose, vert brillant}

Un autre milieu d'étalement en plaque, l'agar-bile lactose vert-brillant, qui n'exige que 17 heures d'incubation, fut proposé par NOBLE et TONNEY (1935) pour appréciation directe sur plaques. C'est essentiellement une forme solide du bouillon bien connu bile-lactose vert-brillant avec addition de divers indicateurs pour permettre la différenciation des colonies de Coli-aerogenes de celles des autres bactéries. Ils indiquèrent que le milieu d'agar donnait des résultats quelque peu meilleurs que ceux obtenus avec le milieu liquide.

\section{Agar ricinoléate citrate}

LItTManN et Stark (1937) imaginèrent un agar ricinoléate citrate utilisant les propriétés inhibitrices envers de nombreuses bactéries non coliformes qui caractérisent le ricinoléate de sodium et l'aptitude des types d'aerogenes-cloacae à utiliser l'acide citrique avec formation d'alcali. De la peptone, de la poudre de lait et du lactose sont compris dans le milieu, tandis que le rouge neutre et le bleu de bromothymol y existent comme indicateurs. Des plaques ensemencées furent mises à l'étude à $37^{\circ}$ pendant 24 heures. Ils indiquent qu'avec ce milieu d'étalement en plaque, il est possible de distinguer Bact. Coli des types d'aerogenes-cloacae, et qu'en recouvrant la plaque d'un précipitant de la protéine, on peut discriminer ces derniers germes des bactéries protéolytiques, telles que Proteus, Serratia et Pseudomonas. 


\section{Agar deoxycholate}

L'agar deoxycholate a été présenté par Leirson (1935) de l'Université John Hopkins, Baltimore, pour l'isolement des pathogènes intestinaux et poür la numération des bacilles Coli et Proteus dans le lait, les produits lactés, l'eau et les eaux d'égoût. Il fut d'abord présenté sous forme déshydratée par le «Baltimore Biological Laboratory Ine. " LeIFson indiquait qu'il donnait des numérations de colonies de bacilles Coli du lait et des produits lactés qui étaient aussi élevées que celles obtenues par les meilleurs des autres milieux et méthodes existants. Des colonies de bacilles Coli et d'autres bactéries étaient rarement prises l'une pour l'autre et la croissance des autres bactéries Gram-positives était inhibée. Les colonies de bactéries Coli-aerogenes se développent rapidement et peuvent être comptées après 15 heures d'incubation à $37^{\circ}$.

YALE (1937), après avoir étudié dix milieux, aussi bien liquides que solides, conclut que l'agar-déoxycholate donne les meilleurs résultats dans l'ensemble pour la détermination de la teneur en Zoli-aerogenes du lait pasteurisé. Il recommanda l'utilisation de la numération sur plaques, mais toutefois seulement quand il était nécessaire de suivre les résultats de tests qualitatifs.

Plus tard, Leifson (1943) trouva que de six sels biliaires essayés, l'hyodeoxycholate de sodium à une concentration de $0,01 \%$ dans le bouillon peptone lactose était celui qui convenait le mieux pour l'estimation des organismes coliformes dans le lait et l'eau. Des colonies coliformes sur agar préparé avec ce milieu et contenant 1 pour 50.000 de rouge neutre étaient d'apparence similaire à celles sur agar deoxycholate.

Malling Olsen (1952) trouva que l'agar deoxycholate était tout à fait sélectif, quoiqu'il eut des difficultés à distinguer entre les colonies de bactéries faisant fermenter le lactose et celles ne faisant pas fermenter le lactose quand on l'utilisait pour les cultures par étalement sur plaques.

BUCHBINDER (1953), rendant compte d'une recherche sur différentes méthodes de détermination de la teneur de la crème glacée en Coli-aerogenes comprenant l'examen de grands nombres d'échantillons dans plusieurs laboratoires des Etats-Unis, indiqua que les résultats prouvaient qu'il était préférablè d'utiliser un milieu solide (agar-lactose-deoxycholate) plutôt qu'un milieu liquide (bouillon bile vert-brillant). La plus forte numération de colonies par millilitre fut donnée par la plus grande quantité de erème glacée utilisée, c'est-à-dire 5 millilitres d'une dilution à 1 pour 10 sur quatre plaques différentes.

Il a été indiqué (Baltimore Biological Laboratory Inc, 1948) 
que l'agar lactose deoxycholate), quoique moins inhibiteur pour les bactéries Gram-positives, donne des numérations des colonies Coli-aerogenes plus élevées que l'agar deoxycholate.

\section{Agar bile rouge-violet}

Au cours de 1932, les Laboratoires Difco, en collaboration avec Mr. H. McCrady, à ce moment vice-arbitre du Comité de Normalisation des méthodes d'analyse du lait de l'Association américaine d'Hygiène publique, entreprit un travail original sur la création d'un milieu sélectif solide pour l'estimation quantitative du nombre d'organismes Coli-aerogenes vivants, dans l'eau, le lait, les produits laitiers et autres produits alimentaires. Le milieu adopté, connu sous le nom d'agar bile rouge-violet fut l'objet d'essais importants dans plusieurs laboratoires américains pour la détermination de la présence et du nombre des organismes Coli-aerogenes dans le lait ot les produits laitiers. BABEL et PARfitT (1936), travaillant sur la crème glacée, trouvèrent qu'il donnait un pourcentage plus élevé d'échantillons positifs et des numérations de Coli-aerogenes plus élevées que l'agar deoxycholate.

Bartram et Black (1936) au cours d'une comparaison simultanée de 10 milieux, trouvèrent que l'agar citrate-ferro-cyanure, l'agar deoxycholate, l'agar Endo et l'agar bile lactose vert-brillant donnaient beaucoup de réactions présomptives fausses ou étaient tout à fait inhibiteurs, ainsi que le prouvait le nombre d'échantillons positifs. Ce furent l'agar bile rouge-violet et l'agar bile rouge neutre qui se montrèrent être les milieux solides les plus satisfaisants et le bile vert-brillant à $2 \%$ le meilleur milieu liquide pour l'isolement des organismes Coli-aerogenes à la fois dans le lait cru et le lait pasteurisé. L'agar bile rouge-violet se montra légèrement meilleur que l'agar bile rouge neutre pour la facilité avec laquelle les colonies de Coli-aerogenes étaient reconnues et il donna dans quelques cas de plus fortes numérations. Les deux dépassaient le bouillon bile vert-brillant en précision et dans le nombre d'échantillons positifs obtenu. Aucun des milieux essayés ne fut satisfaisant au point de vue de l'inhibition complète de la croissance des organismes autres que les Coli-aerogenes.

Mrluer et Pricketr (1938) utilisèrent l'agar bile rouge-violet pour l'examen du lait pasteurisé, et trouvèrent que dans chaque cas quand des colonies typiques rouges purpurines de bactéries Coli-aerogenes se développaient sur le milieu en 18 à 24 heures à $37^{\circ}$, des résultats correspondants confirmés positifs étaient obtenus en 48 heures par ensemencement en bouillon bile vert-brillant suivi par ensemencement en stries sur agar bleu de méthylène à partir des tubes montrant une production de gaz. D'autre part, 
quand des positifs faux étaient obtenus en bouillon bile vertbrillant, aucune colonie typique n'était produite sur l'agar bile rouge-violet.

Tindeman et Smith (1945) comparèrent la méthode du tube de fermentation au ricinoléate en utilisant trois portions de 1 millilitre de lait pasteurisé en bouteille comme inoculum et les méthodes sur plaques au deoxycholate et au milieu bile rouge-violet, tous les tests étant effectués d'après les méthodes normalisées proposées par l'Association américaine d'Hygiène publique (1941). La corrélation entre les résultats obtenus sur 836 échantillons de lait, de crème et de produits laitiers fut très bonne pour les deux milieux solides. Les différences dans la numération obtenue des colonies sont de l'ordre de celles qui peuvent se produire dans les plaques en double sur lesquelles ont été étalés les mêmes milieux et ils conclurent que ces milieux étaient également satisfaisants pour cette utilisation. Des échantillons ne décelant pas de production gazeuse dans aucun des trois cubes de 1 millilitre, $91,6 \%$ ne donnèrent aucune numération de colonie sur agar déoxycholate et de plus, $6,2 \%$ ne donnèrent des numérations que de 1 à 3 colonies, ce qui est une excellente corrélation pour des tests bactériologiques. Jusqu'à $97,8 \%$ des échantillons des tubes à fermentation négatifs donnèrent ainsi des numérations de colonies de 3 ou moins par millilitre. D'un autre côté, seulement $2,4 \%$ des échantillons produisant du gaz dans les 3 portions de 1 millilitre ne donnèrent pas de colonies typiques de Coli-aerogenes en milieu d'agar. Les chiffres comparables pour l'agar bile rouge-violet furent $91,2 \%$ ne montrant pas de colonies typiques pour les échantillons avec des résultats complètement négatifs des tubes à fermentation et seulement $1,9 \%$ des triples échantillons positifs ne donnèrent pas de colonies Coli-aerogenes typiques. Ils montrèrent en outre que 4 ou 5 millilitres de lait peuvent être mis en plaques de façon satisfaisante sur l'un quelconque des milieux solides. L'agar durcissait suffisamment quoiqu'il fût plutôt trouble et, par conséquent, plus difficile à observer pour les numérations. Dans le cas de numérations coliformes faibles, les résultats montrèrent que si on n'étalait qu'une seule plaque les chances d'obtenir un résultat précis étaient plus grandes en utilisant 4 ou 5 millilitres de lait.

DAHLBERG et Coll. (1953) utilisèrent l'agar bile rouge-violet mis à l'étuve pendant 24 heures à $35^{\circ}$ pour la détermination de la teneur en Coli aerogenes aussi bien du lait cru que du lait pasteurisé au cours d'une large enquête sur le contrôle hygiénique du lait dans huit villes des Etats-Unis. Pour obtenir des renseignements sur de faibles nombres de bactéries Coli-aerogenes, 10 millilitres de tous les échantillons de lait furent divisés en trois plaques. 


\section{Agar bleu de méthylène-éosine}

La plupart des milieux sélectifs solides étudiés jusqu'à présent avaient été utilisés pour des cultures par étalement produites par ensemencement, généralement de 1 millilitre de lait ou de 1 millilitre de dilutions de lait. Malling Olsein (1952) étudia une méthode alternative dans laquelle étaient utilisées des oultures en stries produites en enduisant avec du lait ou des dilutions de lait la surface d'une plaque d'agar pré-desséché, solidifié. Cette méthode a le désavantage que la plus grande partie de l'ensemencement quand on utilise une boîte de Petri de dimension normale est généralement de $0 \mathrm{ml}$. 1, quoique $0 \mathrm{ml}$. 2 aient été utilisés avec succès quand la plaque est bien séchée. Il a été prétendu que la méthode de l'ensemencement des surfaces par stries a pour conséquence un plus grand risque de contamination par l'air et qu'elle est sujette à de plus grandes erreurs que la méthode d'étalement en plaque à raison d'une plus grande tendance à une désintégration incontrôlable des agglutinats bactériens, et parce qu'un certain nombre des organismes se collent à l'ensemenceur en verre (DEMETER et Coll., 1953). On a trouvé que la contamination par l'air n'était que peu importante, surtout quand on considère que les bactéries Coli-aerogenes n'existent généralement pas dans l'air du laboratoire (JEPSEN et RоTH, 1950). Les bactéries Coli-aerogenes, quand elles existent en nombre modéré dans le lait, ne montrent pas une grande tendance à former des agglutinats, d'après MALCOLM (1939) et MaLLing OLSEN (1950) et il est prétendu que la seconde assertion est incorrecte car il y a autant de rupture d'agglutinats de bactéries pendant la préparation des dilutions pour la méthode d'étalement que pour la méthode des stries. Il est admis qu'il est impossible de transférer tous les organismes de l'ensemenceur en verre au milieu de culture quand on fait des stries sur une plaque ; mais si on prend soin que tout le liquide soit absorbé par l'agar, ce facteur n'aura qu'un effet léger et constant.

Les deux méthodes devraient donc donner des résultats presque identiques. OLSEN (1945) a trouvé que la méthode des stries en surface donnait un plus grand nombre de bactéries que la méthode d'étalement des plaques et que la méthode du tube de fermentation (dilution) en milieu liquide. Cependant, Maluing OLSen (1952) ne trouva pas de différence appréciablé entre les numérations de colonies de Coli-aerogenes obtenues par les deux méthodes quand des cultures pures dans du lait étaient mises sur plaques sur agar peptone, bouillon de viande. Comme on s'y attendait, la déviation normale était plus grande dans la méthode de culture par stries car $0 \mathrm{ml} .1$ d'ensemencement était utilisé comparé à 1 millilitre dans la méthode d'étalement en plaque; mais la diffé- 
rence était si minime qu'elle n'avait pas d'importance pratique. Il compara en outre la eroissance des bactéries Coli-aerogenes dans les milieux d'agar Endo, bile rouge-violet, deoxycholate, MacConkey, bleu de méthylène-éosine, bleu de méthylène-pourpre de bromo-crésol et phosphate d'ammonium. Le diamètre des colonies sur les milieux d'agar deoxycholate, bleu de méthylèneéosine, bleu de méthylène pourpre de bromo-crésol augmentait à peu près à la même vitesse que sur l'agar de contrôle à $1 \%$ de peptone indiquant que ces milieux n'avaient aucun effet inhibiteur, ou seulement un très léger, sur la croissance des couches de Coliaerogenes examinées.

Pour déterminer l'aptitude des milieux à la mesure de la teneur du lait en bactéries Coli-aerogenes du lait stérile ensemencé avec dix souches différentes de façon à contenir environ 1.000 germes par millilitre, fut ensemencé par stries sur cinq milieux et étalé dans le cas de l'agar peptone $1 \%$, du deoxycholate et de l'agar bile rouge-violet; trente plaques répliques furent utilisées dans chaque cas et l'incubation dura 20 heures à $37^{\circ}$, sauf dans le cas de l'agar-phosphate d'ammonium pour lequel elle dura 48 heures. Le nombre de colonies sur l'agar-bleu de méthylène-éosine, l'agar bleu de méthylène-pourpre de bromo-crésol, l'agar MacConkey et l'agar deoxycholate fut égal, ou presque égal à celui obtenu sur l'agar peptone $1 \%$, tandis que la numération était légèrement plus faible sur l'agar-bile rouge-violet, l'agar Endo et l'agar phosphate d'ammonium que sur l'agar peptone de contrôle.

Pour étudier la capacité de ces milieux à supporter la croissance des bactéries se trouvant normalement dans le lait, des cultures sur bouillon de Micrococcus, Pseudomonas, Achromobacter, Proteus, Alcaligenes Str. lactis, Str. faecalis, Lactobacillus et Bacillus furent ensemencées sur la surface des milieux et les plaques mises à l'étuve pendant $18-20$ heures à $37^{\circ}$. Les milieux étudiés eurent un effet inhibiteur complet, ou presque complet, sur la croissance des bactéries Gram-positives étudiées, à un point tel que les colonies qui apparurent étaient si petites (diamètre max. $0 \mathrm{~mm}$. 2) qu'elles ne pouvaient en aucun cas être prises par erreur pour des colonies de Coli-aerogenes typiques. D'autre part, les bactéries Gramnégatives examinées se développèrent sur tous les milieux; mais leur aspect était tel, qu'à la seule exception d'une souche de Pseudomonas qui forma des colonies d'une couleur rouge foncée sur l'agar Endo, elles ne pouvaient pas être prises pour des colonies de Coli-aerogenes. L'àgar bile rouge-violet fut un des meilleurs milieux examinés, car il accusa les contrastes les plus accentués entre les couleurs ou l'apparence des colonies acidogènes et des colonies non acidogènes. 
Seul l'agar bleu de méthylène-éosine (B.M.E.) fut étudié pour savoir combien des colonies acidogènes étaient des Coli-aerogenes. Une série de 71 échantillons de laits de troupeaux fut ensemencée par stries sur ce milieu, mise à l'étuve pendant $18-20$ heures à $37^{\circ}$ et quelques-unes des colonies acidogènes de chaque plaque ensemencées dans du bouillon peptone lactose. Sur 218 colonies examinées, 214 formèrent du gaz en 48 heures à $37^{\circ}$ dans le bouillon lactosé, tandis que 4 souches ne formaient que de l'acide.

Les colonies sur l'agar B.M.E. qui n'ont pas de centre sombre, mais sont colorées en rose partout, de la même couleur que le milieu, sont composées ou bien de bactéries ne faisant pas fermenter le lactose, ou de bactéries faisant fermenter faiblement le lactose. De 184 souches donnant des colonies colorées en rose, $43,5 \%$ formèrent de l'acide seulement avec le lactose et $4,3 \%$ donnèrent une faible production de gaz. Ces dernières furent trouvées être des souches de Bact. aerogenes type I. Seules, les bactéries Coliaerogenes fortement acidogènes sont ainsi reconnues sur l'agar B.M.E.

Finalement, Matuing OLsen rangea les milieux solides examinés sur les résultats combinés des recherches ci-dessus dans l'ordre suivant : agar bleu de méthylène-éosine, agar-bile-rouge-violet, agar deoxycholate, agar MacConkey, agar pourpre de bromocrésol-bleu de méthylène, agar Endo et agar phosphate d'ammonium. Il observa en outre que l'addition d'environ 5 U.I. de pénicilline par millilitre augmentait la sélectivité de l'agar bleu de méthylène-éosine sans diminuer sa valeur dans le diagnostic différentiel.

Thomas et Cool. (1953), en examinant du lait cru désigné, trouvèrent que seulement $43,1 \%$ sur 65 colonies de plus de $0 \mathrm{~mm}$. 5 de diamètre donnant une précipitation de colorant en 20-24 heures à $37^{\circ}$ sur agar bleu de méthylène-éosine, sur lequel on avait étalé $0 \mathrm{ml} .2 \mathrm{du}$ lait ou de dilution du lait, formaient de l'acide et du gaz en moins de deux jours à $37^{\circ}$ dans le bouillon MacConkey. De meilleurs résultats furent obtenus quand les cultures étaient mises à l'étuve à $30^{\circ}$, car jusqu'à $64,1 \%$ des 268 colonies sombres, avec ou sans reflet métallique, qui se développaient jusqu'à une dimension de $0 \mathrm{~mm}$. 5 ou plus de diamètre en 48 heures à $30^{\circ}$, formèrent de l'acide et du gaz dans le bouillon MaeConkey en moins de cinq jours à $30^{\circ}$. Une plus forte proportion $(74,6 \%)$ des colonies sombres à $30^{\circ}$, formèrent de l'acide et du gaz dans le bouillon MacConkey pendant les mois d'été quand la teneur du lait en Coli-aerogenes du lait était élevée, comparée à $54,0 \%$ des colonies examinées en hiver quand la teneur en organismes Coli-aerogenes était bien plus faible. 


\section{Discussion}

La méthode de dilution du bouillon MacConkey, méthode normale habituelle pour la détermination en Grande-Bretagne de la teneur du lait et de l'eau en Coli-aerogenes et le bouillon bile vert-brillant ou le bouillon ricinoléate-formate, recommandés pour l'examen du lait aux Etats-Unis, ont plusieurs désavantages. La méthode de dilution comporte une très forte erreur d'échantillonnage à moins que de grands nombres de tubes répliques soient utilisés. Des tubes en triple de $0 \mathrm{ml}$. 01 de lait sont généralement utilisés pour les tests présomptifs de Coli-aerogenes du lait oru et des tubes en triple inoculés avec 1 millilitre dans l'examen du lait pasteurisé ; mais l'erreur est néanmoins encore élevée.

BARKWORTH et IRWIN (1943) ont montré que le test présomptif des Coli-aerogenes sous-estime la population dans l'eau et plus encore dans le lait. Ils ensemencèrent de l'eau et du lait trait aseptiquement pour donner à chacun une concentration finale de 0,5 organismes par millilitre; 30 tubes de bouillon MacConkey furent ensuite ensemencés aveo des quantités de 1 millilitre de lait et 30 avec des quantités de 1 millilitre d'eau. La proportion des tubes positifs fut de $27 \%$ avec l'eau et de $23 \%$ et de $19 \%$ avee le lait conservé avant ensemencement, respectivement à $+4^{\circ} 4$ et à $+2202 \mathrm{C}$.

Un type d'organisme Coli-aerogenes peut dépasser en croissance les autres dans des milieux sélectifs, de bouillon ou être trop dilué lorsqu'on procède aux dilutions en série. Ruchноғт et Coll. (1931) ont montré que l'enrichissement préliminaire en bouillon lactosé conduit à des résultats irréguliers et qu'il est préférable, quand on désire avoir des résultats différentiels exacts, d'utiliser les cultures directement des plaques. D'après eux, la prédominance d'un type ou d'un autre pendant l'accroissement est dû à des facteurs tels que l'ensemencement initial, la phase retardatrice, la vitesse de croissance et l'effet des produits du métabolisme. Wilson et Coll. (1935) ont trouvé que Bact. Coli survit plus longtemps que Bact. aerogenes dans le bouillon MacConkey à $37^{\circ}$.

Les milieux sélectifs de bouillon ont un autre désavantage pratique important en ce sens que les résultats ne peuvent pas être obtenus en moins de 48 heures à $37^{\circ}$ et de 72 heures à $30^{\circ}$, alors que la présence d'une fermentation lente ou faible du lactose exige une incubation de 5 à 7 jours à $37^{\circ}$ et de 14 jours à $30^{\circ}$.

Alors que l'erreur d'échantillonnage est bien plus faible avec la méthode de mise en plaque et que les résultats sont obtenus en 18 à 24 heures à $37^{\circ}$ ou à $30^{\circ}$, quelques organismes autres que les bactéries typiques Coli-aerogenes, qui, par définition, sont capables 
de former de l'acide et du gaz du lactose à $30^{\circ}$ ou $37^{\circ}$, sont capables de se développer et de former de l'acide sur tous les milieux sélectifs d'agar qui ont été cités. Si, pour y remédier, le milieu est préparé trop sélectif ou trop inhibiteur, quelques-uns des organismes Coliaerogenes eux-mêmes sont incapables de former des colonies susceptibles d'être comptées.

La revue actuelle de la littérature prouve que ce dernier fait n'est pas un facteur aussi important avec les milieux proposés le plus récemment. Si, à un moment donné, des germes fermentateurs du lactose à $30^{\circ}$ lents ou faibles, donnant les quatre réactions typiques I.M.Vi.C. (Indole - Méthylène réduction, Voges Proskauer - Citrate) sont acceptés comme membres du groupes Coliaerogenes, ou comme organismes ayant une signification au point de vue hygiénique, les milieux solides en plaques peuvent bien avoir un avantage à cet égard, car CUNNINGHAM et GLATHE (1933), Prescott et Coll. (1946) et Thomas et Coll. (1953) ont trouvé que le lait aussi bien que l'eau fournissent quelquefois des numérations élevées de colonies de Coli-aerogenes de ce type d'organisme sur un assez grand nombre de milieux en plaques.

Si on détermine des numérations faibles de colonies de Coli aerogenes en utilisant 1 millilitre ou plus de lait pour l'ensemencement, comme dans le lait nouvellement pasteurisé ou dans le lait cru désigné examiné dans les 4 à 6 heures suivant la traite, il peut y avoir un certain danger à ce que le lait absorbe une quantité considérable du colorant inhibiteur ou fournisse un effet protecteur contre les sels biliaires diminuant ainsi l'action inhibitrice du milieu. Une étude préliminaire de Tномаs et Coll. (1954) a toutefois montré qu'une proportion aussi élevée de colonies rouges foncées sur l'agar bile rouge-violet, mis à l'étuve pendant 20-24 heures à $30^{\circ}$, formait de l'acide et du gaz dans le bouillon MacConkey en 5 jours à $30^{\circ}$ quand 1 millilitre de lait cru utilisé comme ensemencement que lorsque 1 millilitre de dilutions à 0,1 et à 0,01 était examiné.

Puisque aucun des milieux sélectifs pour plaques établis jusqu'à présent n'indique si de grandes colonies formatrices d'acide, précipitant le colorant, sont toutes capables de former du gaz avec le lactose, on ne peut pas s'attendre à ce que les résultats des plaques soient en parfaite corrélation avec ceux obtenus avec des bouillons sélectifs qui indiquent la production de gaz. Néanmoins, une proportion raisonnable des colonies sur agar bile rouge-violet, sur agar deoxycholate et sur agar bleu de méthylène-éosine paraissent être des bactéries Coli-aerogenes typiques et un réexamen de la méthode des plaques est nécessaire en vue des avantages pratiques de cette méthode, en particulier avec incubation à $30^{\circ}$. 
Une telle recherche fournirait également des renseignements utiles en ce qui concerne l'application de la méthode du filtre à membrane utilisée depuis peu pour l'examen des substances contenant relativement peu de bactéries Coli-aerogenes.

\section{RÉFÉRENCES}

American Public Health Association. "Standard methods for the examination of dairy products" (Méthodes officielles pour l'examen des produits laitiers). $8^{\mathrm{e}}$ et $9^{\mathrm{e}}$ éditions, 1941-1948. New York.

S. H. AYERs et P. RUPP. Journal Bact., 1918, 3, 433.

F. J. BABel et E. H. PARfitt. Journal Dairy Sci., 1936, 19, 497.

Baltimore Biological Laboratory Inc. "Culture media for the bacteriological laboratory " (Milieux de culture pour le laboratoire baetériologique). 1948, Baltimore, (U.S.A.).

H. Barkworth et J. O. Irwin. Journal Hyg. Camb., 1943, 43, 129.

M. T. Bartram et L. A. Black. Food Res., 1936, 1, 551.

L. Buchimder. Amer. Journal Publ. Hth. (5, Part 2), 1953, 76.

O. D. H. T. Burke-Gaffney. Journal Hyg. Camb., 1932, 32, 85.

C. H. Chalmers. Journal Hyg. Oamb., 1928, 27, 295.

A. Cunningham et G. Glathe. Rep. Ann. Conf. Soc. Agric. Bact., 1933, 9.

A. C. Dahlberg, H. S. Adams et M. E. Held. "Sanitary Milk Control", Nat, Res. Coun. Pub., 1953, 250.

K. J. Demeter, F. Sauer et M. Miller. Milchw. Forsch., 1933, 15, 265.

C. M. Hillegund. Norsk Vet. Tidsskr., 1943, 55, 104.

M. JARVICK. Int. Dairy Congr, , 1949, 3, 372.

A. Jepsen et H. Roth. Nord. Vet. Med., 1950, 2, 967.

M. Klimmer, G. Haupt et F, Bonchers. Milchw. Forsch, 1929, 9, 236.

E. Leifson. Journal Path. Bact., 1935, 40, 581.

E. Leifson. Journal Bact., 1943, 45, 45.

M. L. Littman ot C. N. StaRk. Journal Bact., 1937, 34, 348.

A. MacConkey. Journal Hyg. Camb., 1906, 6, 385.

J. F. Malcolm. Journal Dairy Res., 1939, 10, 410.

E. Maliting Olsen. Nord. Vet. Med., 1950,2, 271.

E. Malling Olsen. "On coliform bacteria in milk" (Sur les bactéries coliformes du lait). Copenhague, 1952, Kandrup et Wunsch.

A. P. Mathews. Technol. Quart., 1893, 6, 241.

N. J. Miller et P. S. Prickett. Journal Dairy Sci., 1938, 21, 559.

R. E. Noвle. Journal Amer. Wat. Wks Ass., 1928, 19, 733 et F. O. Tonnex. Journal Amer. Wat. Whs Ass., 1935, 27, 108.

E. Olsen. Acta path. microbiol. Scand., 1945, 22, 103.

S. C. Prescott, C. E. A. Winstow, A et M. H. McCrady. "Water Bacterio$\log y$ a (Bactériologie de l'eau). 6th Ed. London : Champan and Hall, 1946.

C. C. Ruchioft, E. W. Coulter, C. L. Adams et A. L. Sotier. Journal Bact., 1933, 25, 143.

C. C. Rechнотt, J. G. Kallas, B. Chinn et E. W. Coulter. Journal Bact., $1931,21,407 ; 22,125$.

RUHMEKORF. Milchw. Forsch, 1931, 11, 600. 
C. E. Skinner et T. J. Murray. Journal Infect. Dis., 1924, 34, 585.

S. B. Thomas, E. P. Davies, R. Brown, et K. Elson. Unpublished date (Renseignements non publiés), 1953.

S. B. Thomas, J. M. Harcombe et K. Elson. Unpublished data (Renseignements non publiés, 1954.

W. D. Tiedeman et S. E. Smith, Journal Milk Tech., 1945, 8, 323.

F. O. Tonnex et R. E. Noble. Journal Amer. Wat. Wks Ass., 1930, 22, 488.

F. O. Tonney et R. E. Noble. Journal Bact., 1932, 23, 473.

G. S. Wilson, R. S. Twigg, R. C. Wright, C. B. Hendry, M. P. Cowell, et I. MAIER. "The Bacteriological Grading of Milk" (Le classement bactériologique du lait). Spec. Rep. Ser. Med. Res. Coun., 1935, 206. London : H. M. Stationery Office.

M. W. YALE. Amer. Journal publ. Hlth., 1937, 27, 564.

\title{
LE REFROIDISSEMENT DU LAIT A LA PRODUCTION (Suite et fin)
}

\author{
par \\ Michel ANQUEZ \\ Ingénieur principal du Génie Rural \\ Chef-adjoint à la Section technique du froid.
}

Appareils utilisant la glace.

L'eau du bac peut aussi être refroidie avec de la glace, l'appareil comprend un compartiment spécial où sont placés les pains de glace. Au moment de la traite, ce compartiment est mis en communication avec le bac à eau glacée dans lequel sont plongés les bidons. La température du lait atteint alors, dans des appareils convenablement dimensionnés, $10^{\circ}$ après la première heure, $4^{\circ}$ après la $2^{\mathrm{e}}$ heure. Ces appareils, qui ont été mis au point dans la région de Bordeaux, sont munis d'un compartiment à denrées (fig. 9).

Le compartiment à glace est calculé en fonction de la quantité de lait à refroidir : pour un appareil recevant 30 à 40 litres de lait, il faut prévoir 25 kilogrammes de glace; pour un meuble destiné à refroidir 120 litres de lait, 50 kilogrammes de glace suffisent. La consommation de glace est, en effet, fonction de la capacité de l'appareil ; elle varie de 800 grammes par litre de lait pour un petit meuble à 400 grammes pour un appareil de grand modèle. Ces chiffres tiennent compte du refroidissement des denrées.

Ce procédé implique un ravitaillement facile et régulier en glace, qui peut provenir, soit d'une fabrique de glace existant dans une localité proche, soit d'une installation créée en annexe de l'usine laitière. La distribution de la glace peut d'ailleurs présenter plusieurs aspects. 